\title{
FISIOLOGIA DA NUTRIÇĀO MINERAL DE Stevia Rebaudiana BERTONI CULTIVADA EM SANTA MARIA, RS, BRASIL.
}

Victor Hugo da Silva e Souza

Departamento de Biologia. Centro de Ciências Naturais e Exatas.UFSM. Santa Maria, RS.

RESUMO

A "stevia" planta nativa do Paraguai e sudoeste do Estado do Mato Grosso do Sul estā sendo cultivada pela primeira vez em São Paulo e, hoje em Santa Maria, Rio Grande do Sul, atravēs de sementei ras e estaquias onde o seu cultivo vem sendo intensificado.

0 presente experimento objetivou estudar a ecofisiologia da Stevia rebaudiana Bertoni, o acúmulo da matēria seca, a absorção de nutrientes minerais e sua distribuição durante o crescimentoe de senvolvimento da "stevia" cultivada em Santa Maria.

SUMMARY

SOUZA, V.H.S., 1988. Physiology of Mineral Nutrition of Stevia re baudiana Bertoni cultived in Santa Maria, RS, Brasil. Ciên cia e Natura, 10:147-153.

The "stevia" a native plant from Paraguay and southwest of Mato Grosso do Sul, Brazil, is being cultivated for the first time in São Paulo. In Santa Maria, Rio Grande do Sul, its culture has increased through sowing and cuttings.

The principal objetive of the work was to study of ecophy siology of Stevia rebaudiana Bertoni, the accumulation of dry matter, absorption and distribution of mineral nutrients in the grawth and. development of Stevia rebaudiana Bertoni cultived in Santa Maria.

INTRODUÇAO

0 cultivo e aproveitamento da Stevia rebaudiana Bertoni tem sido objeto de uma sērie de pesquisas por ser a mesma influenciada pela latitude, temperatura, umidade e outras condições do meio e suas folhas ser retirado um glicosideo de sabor doce conhecido como esteviosīdeo, trezentas vezes mais doce do que a sacarose, que alēm de seu poder adoçante foi-l he atribuido, empiricamente, efeitos de açăo hipoglicemiante, cardiotónicos e reguladores de pressão arte rial.

0 poder adoçante da Stevia rebaudiana Bertoni è conhecido desde milênios e stas folhas foram largamente usadas pelos nativos do Paraguai. o princỉpio ativo steviosideo extraỉdo das folhas da planta por BRIEDEL \& LAVIEILLE (2) mostrou propriedades adulcoran tes e tōnicas.

HUMBOLDT \& BOECK (6) mostram que o steviosideo encontrado nas folhas de Stevia rebaudiana Bertoni é uma droga ativa no sistema 
cārdio-circulatōrio com efeito hipotensor e anti-arritmico nîtido experimentado em ratos; BOECK \& HUMBOLDT (1) estudaram o efeito crō nico do extrato total da "stevia" em individuos normais mostrando que a mesma contém substâncias farmacologicamente ativas oferecendo perspectivas promissoras como droga hipoglicemiante e cardiotónica.

VIANA \& METIVIER (10) utilizando sementes de "stevia" es tudaram värios estágios no desenvolvimento entre a emergência e su cessivos pares de folhas atē um máximo de ārea foliar bem como, as mudanças no nỉvel de proteinas total e açúcares solúveis durante o crescimento das folhas da Stevia rebaudiana Bertoni.

FELIPPE et alii (3) e FELIPPE \& LUCAS (4) preòcupados com a propagação da espēcie em virtude de seu grangle interesse, estuda ram alguns problemas relativos a sua germinação, associada com dois grupos de substāncias promotoras semelhantes me experimento de FRANKLAND \& WAREING (5).

VALIO \& ROCHA (9) estudaram, em plantas cultivadas em São Paulo, as condições de fotoperiodo e reguladores de crescimento pa ra o desenvolvimento vegetativo e reprodutivo, manipulando a planta visando produzir sementes para a propagação ou folhas para a pro dução do esteviosĩdeo.

SAKAGUCHI \& KANT (7), revisando trabalhos japoneses sobre a "stevia", abordam características fisiológicas do crescimento e cultura da planta. SUMITA, citado pelos mesmos autores, determinou a absorção de alguns elementos essenciais e suas propriedades quĩmi cas, métodos de dosagem e inocuidade do componente doce da "stevia" - o esteviosideo.

\section{MATERIAL E METODOS}

\section{Condições do Meio}

0 material para anālise foi coletado de plantas de Stevia rebaudiana Bertoni cultivada no "CAMPUS" da Universidade Federal de Santa Maria, cidade situada na ārea geogräfica do Rio Grande do Sul da "DEPRESSAO CENTRAL" cujos fatores meteorolōgicos variaram de uma temperatura māxima de $38^{\circ} \mathrm{C}$ e mīnima de $2{ }^{\circ} \mathrm{C}$ e uma precipitação plu viométrica de $850 \mathrm{~mm}$ no período de agosto de 1981 a julho de 1982.

Caracteristicas Estudadas

Procurou-se determinar as seguintes caracteristicas:

Informações sobre amostragem, peso seco (g) e àrea foliar $\left(\mathrm{cm}^{2}\right)$, estágios de crescimento e do desenvolvimento e, os teores de alguns elementos minerais da parte aérea da variedade stevia rebau diana Bertoni.

Análises de boratório

As plantas coletadas de 30 em 30 dias, na primeira hora da manhä, eram constituĩdas de amostras da parte aérea de plantas 
de Stevia rebaudiana Bertoni cultivada em Santa Maria.

No laboratório após lavagens sucessivas eram determinadas as àreas foliares constituindo de uma amostra de 20 folhas e que, apōs secagem, serviam para a determinação do seu peso seco e para a preparação das soluções minerais pelo mētodo descrito por souzA (8).

Da parte aérea constituỉda de folhas, ramos foliares mais velhos e mais novos, flores e ramos florais foram feitas anālises quimicas de sete elementos minerais segundo as tëcnicas para o po tássio, o cálcio, o magnésio, o manganès, o ferro, o zinco e o co bre, para a leitura em espectrofotómetro de absorção atōmica -PERKIN - ELMER 303.

\section{RESULTADOS E DISCUSSAO}

Os resultados sobre a variação no peso do material seco, àrea foliar e estāgios do crescimento e do desenvolvimento das plan tas de Stevia rebaudiana Bertoni, cultivada em Santa Maria, estão descritos na Tabela. I e, representados graficamente pela Figura 1.

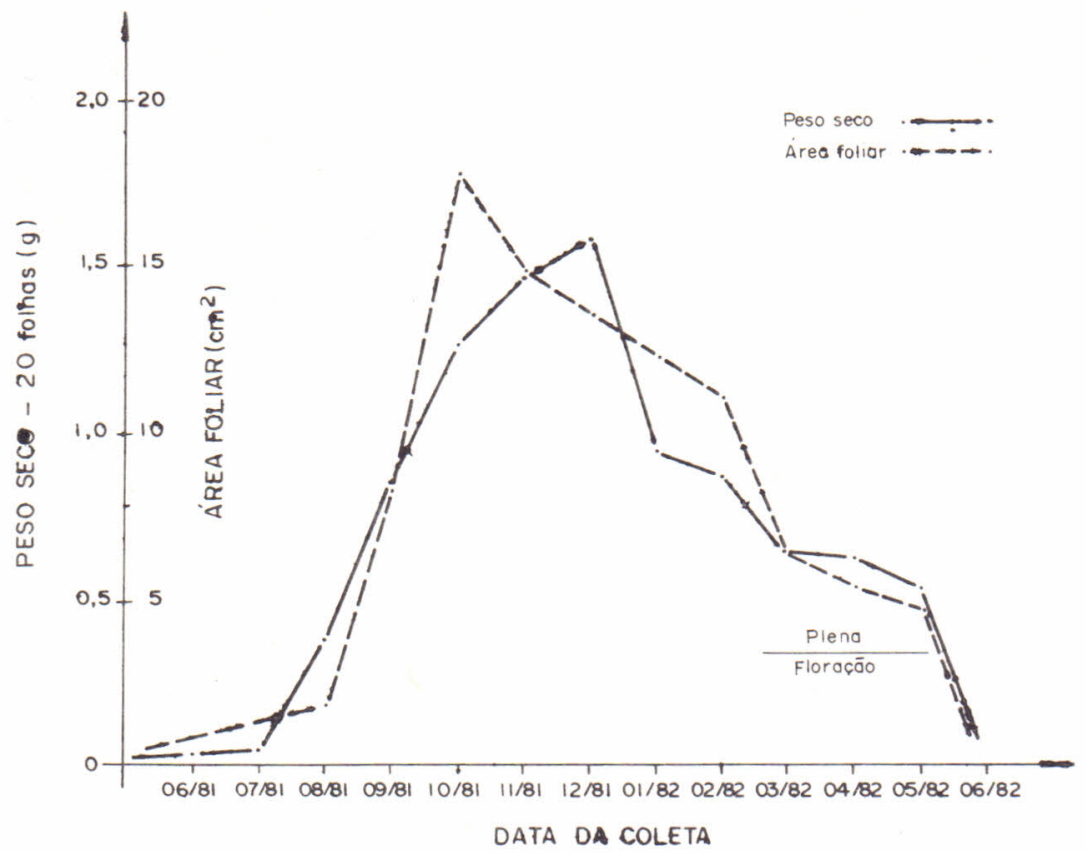

Figura 1 - Variação do peso seco (g) e ärea foliar (cm²) em plantas de Stevia rebaudiana Bertoni, cultivada em Santa Maria, RS, na estação de crescimeroto e de desenvolvimento de $1981 / 82$.

Verifica-se que o acūmulo da matēia seca é relativamente contỉnuo, com uma exigência bastante tida de àgua a medida que se 
TABELA I - DATA DAS AMOSTRAGENS, PESO SECO (g) AREA FOLIAR ( $\left.\mathrm{cm}^{2}\right)$ E ESTAGIOS DE CRESCIMENTO E DESENVOLVIMENTO DE J̈̈ PLANTAS DE Stevia rebaudiana BERTONI, CULTIVADA EM SANTA MARIA, RS, EM 1981/82.

\begin{tabular}{|c|c|c|c|}
\hline Epoca de coleta & & & \\
\hline da amostra & $\begin{array}{c}\text { peso seco } \\
(\mathrm{g})\end{array}$ & $\begin{array}{c}\text { àrea faliar } \\
\left(\mathrm{cm}^{2}\right)\end{array}$ & DESEN VOLVIMENTO \\
\hline $07 / 1981$ & - & - & Ramos novos em crescimento e iniciação foliar \\
\hline $08 / 1981$ & 0.384 & 1.82 & Folhas novas, frāgeis, levemente adocicadas \\
\hline $09 / 1981$ & .0 .855 & 8.10 & Folhas frägeis com um verde pouco intenso, levemente adocicadas \\
\hline $10 / 1981$ & 1.284 & 17.80 & Folhas rigidas, verde intenso, gosto adocicado pronunciado \\
\hline $11 / 1981$ & 1.477 & 14.87 & Folhas rïgidas, algumas flores esporādicas* \\
\hline $12 / 1981$ & 1.595 & 13.76 & $\begin{array}{l}\text { Folhas rígidas, gosto adocicado pouco pronunciado quando no } \\
\text { estado fresco, bem pronunciado no estado seco }\end{array}$ \\
\hline $01 / 1982$ & 0.976 & 12.06 & Idem \\
\hline $02 / 1982$ & 0.890 & 11.06 & Idem \\
\hline $03 / 1982$ & 0.655 & 6.64 & Alguns ramos florais \\
\hline $04 / 1982$ & 0.625 & 5.30 & Plena floração \\
\hline $05 / 1982$ & 0.541 & 4.92 & Floração seca \\
\hline $06 / 1982$ & - & - & $\begin{array}{l}\text { Ramos novos em crescimento, algumas folhas secas, restos flo } \\
\text { rais }\end{array}$ \\
\hline
\end{tabular}

* Observações idénticas em $11 / 1982$. 
TABELA II - CONCENTRAÇÃO DE NUTRIENTES NA MATERIA SECA DA PARTE AEREA DE PLANTAS DE Stevia rebaUdiana BERTONI, CULTIVADA EM SANTA MARIA, RS.

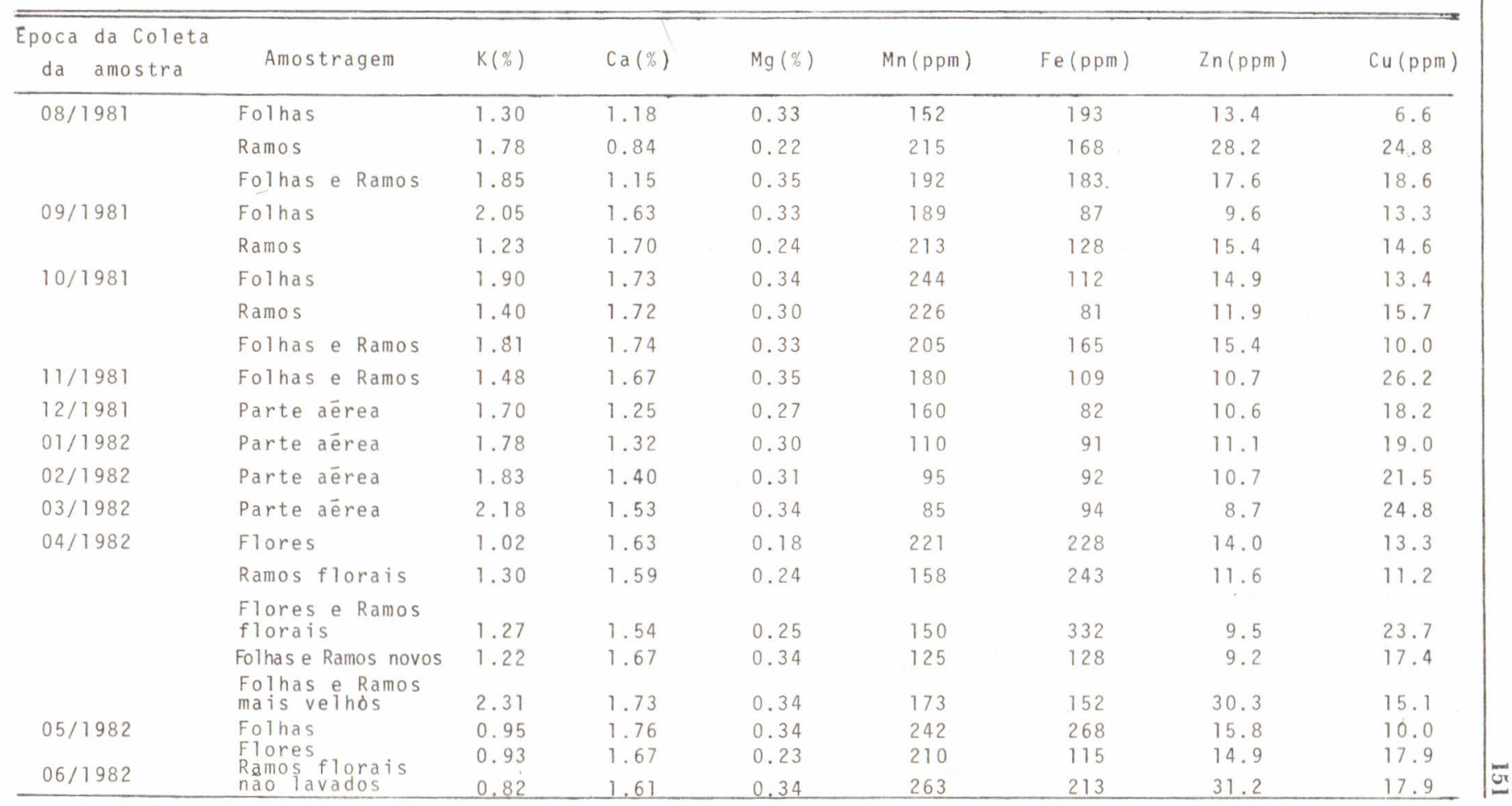


processa o desenvolvimento da planta, o que é comprovado pela absor ção dos nutrientes e pelo acúmulo dos produtos tofossintetizantes. Confirma o presente experimento as pesquisas de VALIO \& ROCHA de que a stevia é uma planta de dias curtos quando o fotoperiodo di minui a partir de fevereiro e as plantas jā estão em plena matura ção para a floração.

Os dados sobre a variação na concentração dos macros e micronutrientes na matéria seca obtidos das amostragens dos diferen tes estágios da stevia estão relacionados na Tabela II. Mostram pe quenas oscilações. conforme o órgão estudado, mas tendem a uma esta bilização e, com isso, comprovam a absorção continua de todos os ma cros e micronutrientes durante o desenvolvimento da mesma. Dentre os macronutrientes o potássio (K) foi solicitado em maior quantida de, seguindo-se o cálcio (Ca) e o magnésio (Mg); os micronutrientes foram exigidos constantemente.

CONCLUSOES

A Stevia rebaudiana Bertoni $\bar{e}$ uma planta de dias curtos.

Todos os macros e micronutrientes estudados foram exigi dos continuamente durante todo o ciclo vegetativo da Stevia rebau diana Bertoni, mostrando o acúmulo de nutrientes nos diferentes es tágios do crescimento e desenvolvimento da planta.

\section{BIBLIOGRAFIA CITADA}

1. BOECKH, E.M.A. \& HUMBOLdT, G. Avaliação clínica do efeito crônico do edulcorante natural Stevia rebaudiana Bertoni sobre teste de tolerância a glicose, parâmetros clinnicos e eletrocardio gräficos em indivîduos normais. Revista Ciência e Cultura. São Pau10, 32:208-210, 1978 .

2. BRIEDEL, M. \& LAVIEILLE, R. Sur le principe sucré des feuilles de Kaā-hê-è (Stevia rebaudiana Bert.) Buzl Soc.Chim. Biol. Paris, $13: 636-655,1931$.

3. FELIPPE, G.M.; LUCAS, N.M.; BEhAR, L.; OLIVEIRA, M.A.C. Observa ções a respeito da germinação de Stevia rebaudiana Bert. Re vista Hoehnea. São Paulo, 1:81-93. 1971.

4. Felippe, G.M. \& LUCAS, N.M. Estudo da viabilidade dos frutos de Stevia rebaudiana Bert. Revista Hoehnea. São Paulo, 1:95-105, 1971.

5. FRANKLAND, B. \& WAREING, P.F. Effect of gibberellic acid in hypo cotyl growth of lettuce seedling. Nature, London, 185:255-256, 1960.

6. HUMBOLdT, G. \& BOECKh,E.M.A. Steviosỉdeo: efeito cārdio-circulą tōrio em ratos. Revista Ciência e Cultura. São Paulo, 32:206207, 1978.

7. SAKAGUCHI, M. \& KANT, T. As pesquisas japonesas com Stevia rebaudiana 
(Bert.) Bertoni e o Esteviosỉdeo. Revista Ciência e Cultura. São Paulo, 34(2):235-248, 1982.

8. SOUZA, V.H.S. Variações no teor de alguns elementos minerais nas folhas e frutos de café (Coffea arabica L. var. "Mundo Novo"). Revista Ceres, Viçosa, 22(123), 1975.

9. VALIO, J.F.M. and ROCHA, R.F. Effect of photoperiod and growth regulator on growth and flowring of Stevia rebaudiana Berto ni. Japan.Jour. Crop.Sei. 46(2):243-248, 1977.

10. VIANA, A.M. and METIVIER, J. Changes in the levels of total so luble proteins and suggars during leaf ontogeny in stevia re baudiana Bert. Ann. Bot. 45:469-474, 1980.

Recebido em outubro, 1988; aceito em novembro, 1988. 
